\title{
An unusual cause of abdominal pain
}

\author{
Aileen Mc Cabe, ${ }^{1}$ Justin Low, ${ }^{2}$ John Mclnerney ${ }^{3}$ \\ ${ }^{1}$ Emergency Department, St James Hospital, Dublin, Ireland; \\ 2Department of Infectious Diseases, Mater Misericordiae University Hospital, Dublin, Ireland; \\ 3Emergency Department, Mater Misericordiae University Hospital, Dublin, Ireland
}

Correspondence to Aileen Mc Cabe, lifesbeachy@yahoo.com

\begin{abstract}
Summary
A 26-year-old man presented to the Emergency Department with abdominal pain, diarrhoea, anorexia and haematemesis. The patient was previously diagnosed with latent tuberculosis (TB). On examination, his abdomen was diffusely tender, with localised guarding in the right iliac fossa. CT imaging of his abdomen and pelvis demonstrated a low volume of ascites, diffuse studding of the peritoneum, omental caking and several bulky low-density lymph nodes in the retroperitoneum. A laparoscopy was performed to obtain a peritoneal biopsy. Histology demonstrated fragments of peritoneum with necrotising granulomatous inflammatory infiltrate in keeping with an infectious process, favouring TB. He was commenced on rifampicin, isoniazid, pyrazinamide, ethambutol and pyridoxine under the direct observed therapy by the infectious diseases team. In view of his extensive peritoneal involvement, he was empirically started on high-dose prednisolone for symptomatic control and to reduce complications related to peritoneal adhesions.
\end{abstract}

\section{BACKGROUND}

Signs and symptoms of peritoneal tuberculosis (TB) are non-specific. This presents challenges to the physician and demonstrates the importance of keeping peritoneal TB as a differential diagnosis, particularly if the patient has a history of TB or is in close contact with people with TB.

\section{CASE PRESENTATION}

A 26-year-old man presented to the Emergency Department with a 1-month history of persistent abdominal pain and a 1-day history of haematemesis, diarrhoea and not being able to tolerate oral diet.

$\mathrm{He}$ is of South African origin but has been living in Ireland for more than 5 years. In 2004, his mother was diagnosed and treated for pan-sensitive pulmonary TB. At that time, the patient was screened and diagnosed with latent TB by the public health team. He was offered treatment from which he defaulted.

Ten weeks earlier, he had presented to the Emergency Department with a 4-month history of non-productive cough, night sweats and weight loss of $12 \mathrm{~kg}$. He was referred to the $\mathrm{TB}$ clinic with a clinical suspicion of $\mathrm{TB}$. There, he had three sets of sputum that were negative for TB and a normal chest x-ray. A bronchoscopy was arranged but he again defaulted from his appointment and subsequent follow-up.

On examination, the patient looked cachectic. His heart rate was $118 \mathrm{bpm}$, temperature $36.7^{\circ} \mathrm{C}$ and blood pressure 125/86 mm Hg. Cardiovascular and respiratory examinations were unremarkable. His abdomen was diffusely tender, with localised guarding in the right iliac fossa.

\section{INVESTIGATIONS}

Baseline full blood count and urea and electrolytes were normal. His liver function test results were $\gamma$-glutamyltransferase $105 \mathrm{IU} / \mathrm{l}$, bilirubin $9 \mu \mathrm{mol} / \mathrm{l}$, alkaline phosphatase 80 IU/l, alanine aminotransferase 17 IU/1 and amylase $68 \mathrm{IU} / 1$.

He underwent a double-contrast CT imaging of his abdomen and pelvis (figure 1). This demonstrated a low volume of ascites, diffuse studding of the peritoneum and omental caking with several bulky low-density lymph nodes in the retroperitoneum.

A laparoscopy was performed to obtain a peritoneal biopsy. The histology demonstrated fragments of peritoneum with necrotising granulomatous inflammatory infiltrate. The findings are most in keeping with an infectious process, favouring TB.

\section{TREATMENT}

The care of the patient was subsequently taken over by the infectious diseases team that began treatment of the patient with rifampicin, isoniazid, pyrazinamide, ethambutol and pyridoxine under direct observed therapy (DOT). In view of his extensive peritoneal involvement, he was empirically started on high-dose prednisolone $60 \mathrm{mg}$ once daily for symptomatic control and to reduce subsequent risk of complications related to peritoneal adhesion. ${ }^{1} \mathrm{He}$ was discharged on DOT with good reported adherence to treatment.

\section{OUTCOME AND FOLLOW-UP}

He was readmitted 6 weeks later with severe abdominal pain and acutely raised $C$ reactive protein at 265 , when he ran out of his prescription for prednisolone. His symptoms resolved on re-commencement of steroid. He was weaned of steroid very slowly over the next 4 months.

Unfortunately, his peritoneal biopsy did not grow anything, but due to his clinical improvement on the standard $\mathrm{TB}$ treatment and the reassuring fact that his mother had a pan-sensitive TB in 2004, he is being treated for a presumptive pan-sensitive TB with a planned duration of treatment of 1 year. 


\section{BMJ Case Reports}

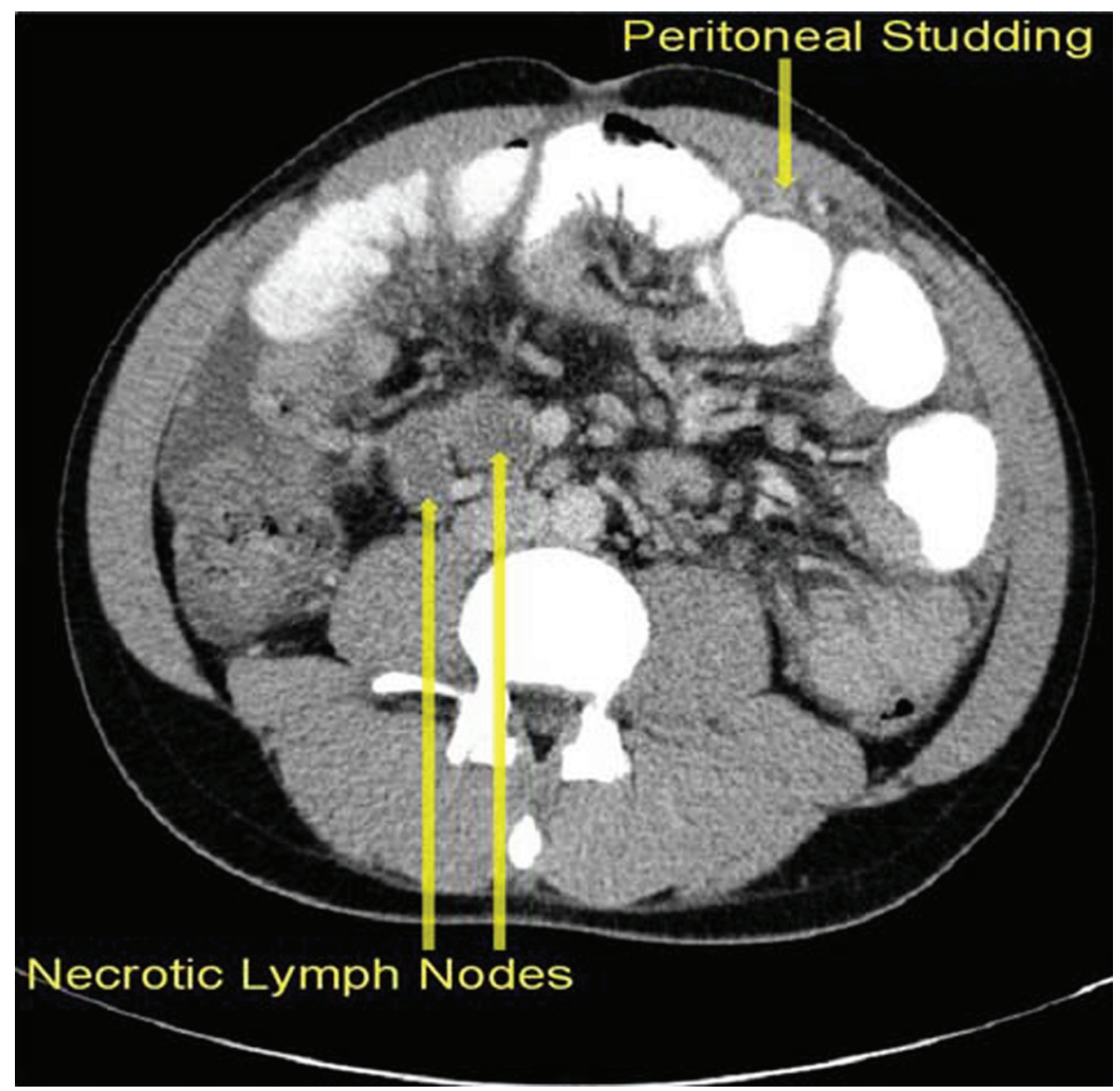

Figure 1 Double-contrast abdominal CT image (5-mm slice) demonstrating peritoneal studding and necrotic lymph nodes.

\section{DISCUSSION}

This case demonstrates a rare example of peritoneal TB presenting as abdominal pain to the Emergency Department. The patient had a history of latent TB and prior to his presentation had been extensively investigated for evidence of pulmonary TB with no positive findings.

The national crude incidence rate of $\mathrm{TB}$ in Ireland is $10.6 / 100000$ population. In the most recent report published by the health protection surveillance centre, it was noted that of 450 cases of TB notified in 2005, 278 (61.9\%) were pulmonary, $130(29.0 \%)$ were extrapulmonary and 41 (9.1\%) were pulmonary and extrapulmonary. Specifically, there were five documented cases of peritoneal TB $(2.9 \%$ of all extrapulmonary cases). ${ }^{2}$

The incidence of peritoneal TB in the developed world is linked with increasing travel and migration and also to the rising number of patients with HIV who are susceptible to opportunistic infections.

Peritoneal TB is a subacute disease and its symptoms evolve over a period of several weeks to months. Common findings found in a previous case series include weight loss (81\%), weakness (81\%), abdominal mass (72\%), abdominal pain $(72 \%)$, abdominal distension (63\%), anorexia and night sweats $(36 \%){ }^{3}$ All of these symptoms were experienced by our patient.

The postulated mechanisms by which the tubercle bacilli reach the gastrointestinal tract include haematogenous spread from the primary lung focus in childhood, with later reactivation; ingestion of bacilli in sputum from active pulmonary focus; and direct spread from adjacent organs and through lymph channels from infected nodes. ${ }^{3}$

Diagnostic tests include common tests for TB imaging chest radiographs, CTs, positive tuberculin skin test and ascitic fluid tests (lactate dehydrogenase, adenosine deaminase $>30 \mathrm{U} / \mathrm{l}$, smear and culture). However, the gold standard for diagnosis remains laparoscopy with visual diagnosis, histology and microbiological culture to determine drug susceptibility. ${ }^{4}$

\section{Learning points}

- Signs and symptoms of peritoneal TB are non-specific.

- The incidence of peritoneal TB in the developed world is linked with increasing travel and to the rising number of patients with HIV.

- The gold standard for diagnosis remains laparoscopy with visual diagnosis, histology and microbiological culture to determine drug susceptibility.

- Physicians need to have a high index of suspicion of peritoneal TB if the patient has a history of TB or is in close contact with people with TB. 


\section{BMJ Case Reports}

Treatment is solely pharmacological and is continued for $\geq 6$ months. The addition of steroid in the first 3 months of treatment may reduce the incidence of late complications arising from adhesion, such as small bowel obstruction. However, it is usually avoided because of the risk of tuberculous dissemination in the setting of multidrug resistance.

\section{Competing interests None.}

Patient consent Obtained.

\section{REFERENCES}

1. Alrajhi AA, Halim MA, al-Hokail A, et al. Corticosteroid treatment of peritoneal tuberculosis. Clin Infect Dis 1998;27:52-6.

2. Health Protection Surveillance Centre. Report on the Epidemiology of Tuberculosis in Ireland 2005.

3. Braun MM, Byers RH, Heyward WL, et al. Acquired immunodeficiency syndrome and extrapulmonary tuberculosis in the United States. Arch Intern Med 1990;150:1913-16.

4. Uzunkoy A, Harma M, Harma M. Diagnosis of abdominal tuberculosis: experience from 11 cases and review of the literature. World J Gastroenterol 2004; 10:3647-9.

This pdf has been created automatically from the final edited text and images.

Copyright 2011 BMJ Publishing Group. All rights reserved. For permission to reuse any of this content visit http://group.bmj.com/group/rights-licensing/permissions.

BMJ Case Report Fellows may re-use this article for personal use and teaching without any further permission.

Please cite this article as follows (you will need to access the article online to obtain the date of publication).

Mc Cabe A, Low J, McInerney J. An unusual cause of abdominal pain. BMJ Case Reports 2011;10.1136/bcr.09.2010.3370, date of publication

Become a Fellow of BMJ Case Reports today and you can:

- Submit as many cases as you like

- Enjoy fast sympathetic peer review and rapid publication of accepted articles

- Access all the published articles

- Re-use any of the published material for personal use and teaching without further permission

For information on Institutional Fellowships contact consortiasales@bmjgroup.com

Visit casereports.bmj.com for more articles like this and to become a Fellow 